\title{
Accumulation of advanced glycation end products in the rabbit blastocyst under maternal diabetes
}

\author{
Elisa Haucke, Alexander Navarrete Santos ${ }^{1}$, Andreas Simm ${ }^{1}$, Christian Henning ${ }^{2}$, \\ Marcus A Glomb², Jacqueline Gürke, Maria Schindler, Bernd Fischer and Anne Navarrete Santos \\ Department of Anatomy and Cell Biology, Faculty of Medicine, Martin-Luther-University Halle-Wittenberg, \\ Grosse Steinstrasse 52, 06108 Halle (Saale), Germany, ${ }^{1}$ Department of Cardiothoracic Surgery, Martin-Luther- \\ University Halle-Wittenberg, Ernst Grube Strasse 40, 06120 Halle (Saale), Germany and ${ }^{2}$ Institute of Chemistry, \\ Food Chemistry, Martin-Luther-University Halle-Wittenberg, Kurt-Mothes Strasse 2, 06120 Halle (Saale), Germany \\ Correspondence should be addressed to E Haucke; Email: elisa.haucke@medizin.uni-halle.de
}

\begin{abstract}
Diabetes mellitus (DM) during pregnancy is one of the leading causes of perinatal morbidity and birth defects. The mechanism by which maternal hyperglycemia, the major teratogenic factor, induces embryonic malformations remains unclear. Advanced glycation end products (AGEs) are known to accumulate during the course of DM and contribute to the development of diabetic complications. Employing a diabetic rabbit model, we investigated the influence of maternal hyperglycemia during the preimplantation period on AGE formation (pentosidine, argpyrimidine, and $N^{\varepsilon}$-carboxymethyllysine (CML)) in the reproductive tract and the embryo itself. As a consequence of type $1 \mathrm{DM}$, the AGE levels in blood plasma increased up to $50 \%$, correlating closely with an AGE accumulation in the endometrium of diabetic females. Embryos from diabetic mothers had increased protein-bound CML levels and showed enhanced fluorescent signals for AGE-specific fluorescence in the blastocyst cavity fluid (BCF). The quantification of CML by HPLC-mass spectrometry (MS/MS) showed a higher amount of soluble CML in the BCF of blastocysts from diabetic rabbits $(0.26 \pm 0.05 \mu \mathrm{mol} / \mathrm{l})$ compared with controls $(0.18 \pm 0.02 \mu \mathrm{mol} / \mathrm{l})$. The high amount of $\mathrm{AGEs}$ in blastocysts from diabetic mothers correlates positively with an increased AGER (receptor for AGE (RAGE) mRNA expression. Our study gives alarming insights into the consequences of poorly controlled maternal diabetes for AGE formation in the embryo. Maternal hyperglycemia during the preimplantation period is correlated with an increase in AGE formation in the uterine environment and the embryo itself. This may influence the development of the embryo through increased AGE-mediated cellular stress by RAGEs.
\end{abstract}

Reproduction (2014) 148 169-178

\section{Introduction}

Approximately $7 \%$ of pregnancies are complicated due to diabetes mellitus (DM; American Diabetes Association 2013). Increasing obesity rates are a serious risk factor for type $2 \mathrm{DM}$ and gestational DM (American Diabetes Association 2013). DM during pregnancy is of great concern as it is a major cause of perinatal morbidity and mortality (Combs \& Kitzmiller 1991, Greene 1999). Although our understanding and management of DM have improved during the last decades, diabetic pregnancies are still reported to have numerous adverse effects (Combs \& Kitzmiller 1991, Aberg et al. 2001, Eriksson et al. 2003, Corrigan et al. 2009). Hyperglycemia is considered as a major teratogenic factor for congenital malformation, although other associated factors such as ketone bodies, branched amino acids, and triglycerides have also been shown to exert adverse effects on the developing embryo (Eriksson et al. 2000). However, it is not yet clear in which way maternal hyperglycemia affects prenatal embryo development.
There is upcoming evidence that advanced glycation end products (AGEs) might play a critical role in diabetic pregnancies.

AGEs are a complex group of compounds formed via non-enzymatic reactions between reducing sugars and $\mathrm{N}$-terminal amino groups on proteins, lipids, and nucleic acids. End-stage products of the protein glycation can be divided into fluorescent AGEs (such as argpyrimidine), non-fluorescent AGEs (such as $N^{\varepsilon}$-carboxymethyllysine $(\mathrm{CML})$ ), and cross-linking compounds (such as pentosidine). Owing to the intrinsic fluorescence of some AGEs, plasma and tissue fluorescence can be used as markers for AGE accumulation (Goh \& Cooper 2008, Bos et al. 2011). Formation and accumulation of AGEs are related to aging as well as to prolonged hyperglycemia and oxidative stress resulting from DM (Sell et al. 1991, Lee \& Cerami 1992, Dyer et al. 1993, Brownlee 1995).

AGEs are identified to play a role in the development of diabetic complications such as diabetic nephropathy, cardiomyopathy, atherosclerotic disease, peripheral neuropathy, and ocular disease (Ahmed \& Thornalley 2007, 
Nass et al. 2007). The post-translational modification of proteins by reducing sugars alters their biological structure and function and leads not only to a loss of molecular function but also to a reduced degradation of these damaged proteins. An additional proposed mechanism of AGE-induced damage is the release of reactive oxygen species, particularly superoxide and hydrogen peroxide by AGEs (Carubelli et al. 1995, Ortwerth et al. 1998). AGEs are able to activate intracellular cascades by binding specific receptors, for example, the receptor for AGEs (RAGEs). AGE-RAGE interactions induce a broad spectrum of signaling mechanisms such as p21ras, Erk1/2 MAP kinases (MAPKs), p38 and SAPK/JNK MAPKs, Rho GTPases, PI3K, and the JAK/STAT pathway (Bierhaus et al. 2005, Rouhiainen et al. 2013). Downstream consequence is the activation of nuclear factor $\kappa \mathrm{B}(\mathrm{NF} \kappa \mathrm{B})$ that results in the release of pro-inflammatory mediators such as free radicals and cytokines (Berbaum et al. 2008). AGER (RAGE) has been shown to be expressed in the rabbit blastocyst, at mRNA and protein levels (Ott et al. 2014).

Women with gestational DM have significantly higher serum AGE levels compared with healthy controls, whereas women with types 1 and $2 \mathrm{DM}$, in good medical supervision, show normal AGE levels (Buongiorno et al. 1997). There is a strong relationship between mothers and neonates regarding AGEs. In women with gestational DM, high levels of AGEs and advanced oxidation protein products (AOPPs) are also detectable in the umbilical blood of their neonates. Both, diabetic mother and neonate, showed higher AGE and AOPP levels compared with healthy controls (Boutzios et al. 2013). Elevated AGE levels in women with gestational DM are associated with pregnancy complications such as birth asphyxia, congenital malformations, or stillbirth (Guosheng et al. 2009). The harmful effects of AGEs after implantation and placentation are likely to threaten the embryo/fetus too, as maternal hyperglycemic blood is connected to the blood system of the embryo. However, this study demonstrates that the preimplantation period is also of great importance on AGE formation, especially in mothers with poorly controlled preexisting DM.

The preimplantation period is a critical ontogenetic stage in embryo development and highly vulnerable for teratogenesis. At this period, the embryo is most sensitive to its surrounding milieu, especially to deregulations by external stimuli (Watkins et al. 2008). In this study, we investigated the influence of a poorly controlled maternal type 1 DM on AGE formation in preimplantation embryos and in the reproductive tract employing a rabbit model. As the rabbit blastocyst implants at day 6.8 post coitum (p.c.), we recovered the blastocysts before, i.e. at day 6.0 p.c. At this time, the rabbit blastocyst is covered by an extraembryonic mucin layer (Fischer et al. 1991, Herrler et al. 2002). However, this layer does not interfere with glucose uptake and metabolism in vivo and in vitro (Fischer et al. 2010, Ramin et al. 2010,
Schindler et al. 2013). We show that DM not only is critical for maternal metabolism but also affects the AGE accumulation and AGER mRNA levels in the developing embryo even before implantation.

\section{Materials and methods}

\section{Alloxan treatment and allocation of samples}

All animal experiments were performed in accordance with the principles of laboratory animal care and the experimental protocol was approved by the Local Ethical Commission of the 'Landesverwaltungsamt Dessau' (reference number: 42502-2-812).

Experimental type 1 DM was induced by alloxan (SigmaAldrich) treatment as described previously (Ramin et al. 2010). Rabbits were allowed to eat ad libitum. The blood glucose level of females with type $1 \mathrm{DM}$ increased 1 day after alloxan administration and was kept in a range between 20 and $30 \mathrm{mmol} / \mathrm{l}$ by insulin supplementation (Huminsulin, basal (NPI), Lilly, Gießen, Germany; three times per day). The duration for the poorly controlled type 1 DM was $\sim 10$ days before mating and during the 6 days of pregnancy. On average, diabetic rabbits had a 4.5 -fold higher blood glucose concentration in comparison to the normoglycemic reference group (27.6 \pm 0.5 and $6.2 \pm 0.1 \mathrm{mmol} / \mathrm{l}, P<0.001$; Fig. 1$)$.

Follicle growth was stimulated by s.c. injection of $110 \mathrm{IU}$ pregnant mare's serum gonadotropin (Intervet, Unterschleißheim, Germany) and ovulation was ensured by i.v. injection of $75 \mathrm{IU}$ human chorionic gonadotropin (Intervet) after mating with fertile males. Samples from diabetic and normoglycemic rabbits were obtained 6 days after mating (p.c.). Rabbits were killed by an overdose of pentobarbital (SigmaAldrich) and exsanguination. Later, we obtained maternal blood, maternal tissues, and the blastocysts. The blastocysts were flushed out of the uteri and washed three times with PBS to avoid contamination of blastocyst samples with uterine tissue.

\section{Protein preparation of blastocysts and AGE detection by slot blot analyses}

For protein extraction, a group of eight to ten blastocysts from at least three mothers were randomly pooled, dissolved in RIPA
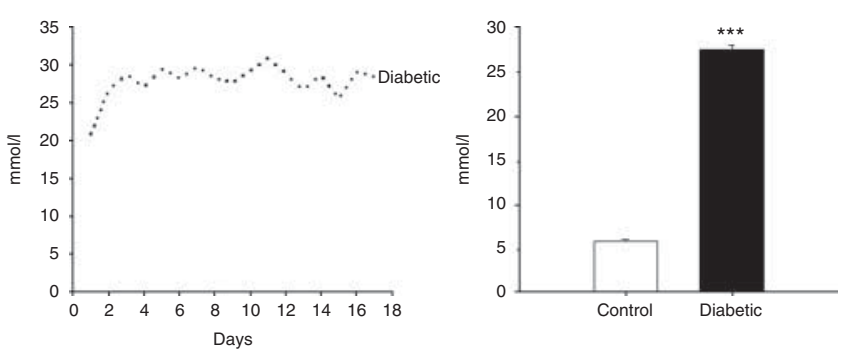

Figure 1 (A) Blood glucose levels after alloxan injection (day 0) in rabbits. The blood glucose level was monitored using commercially available blood glucose test strips three times a day. Data are shown as an average of nine animals with three measured data each per day (mean \pm S.E.M., $\left.{ }^{* * *} P<0.001\right)$. 
lysis buffer (PBS, 1\% vol/vol NP-40, 0.5\% wt/vol sodium deoxycholate, and $0.1 \% \mathrm{wt} / \mathrm{vol}$ SDS), and homogenized with a syringe (Omnifix 40 Duo, Braun, Melsungen, Germany). After incubation on ice for $30 \mathrm{~min}$, the samples were centrifuged at $13000 \mathrm{~g}$ for $20 \mathrm{~min}$. The supernatant was stored at $-80{ }^{\circ} \mathrm{C}$ until use for slot blot analysis.

Slot blot analyses were performed with $25 \mu \mathrm{g}$ protein. Denatured protein samples (heated for $10 \mathrm{~min}$ at $80^{\circ} \mathrm{C}$ ) were spotted onto a nylon membrane (GE Healthcare, München, Germany) using a slot blot apparatus (Biostep, Rabenau, Germany). The protein load was determined by Ponceau $\mathrm{S}$ staining. After blocking with 5\% milk/TBS-T for $1 \mathrm{~h}$, the membrane was incubated with monoclonal mouse antibodies against CML, argpyrimidine, or pentosidine (1:100, Biologo, Kassel, Germany), respectively, overnight at $4{ }^{\circ} \mathrm{C}$. Samples were rinsed three times with TBS-T for $5 \mathrm{~min}$ and subsequently incubated with a secondary goat anti-mouse IgG for $1 \mathrm{~h}$ (Dianova, Hamburg, Germany). The immunoreactive signal was visualized by ECL detection (Millipore, Schwalbach, Germany) and quantified by Fusion FX7 and the corresponding software Fusion 15.18. Protein modification rate was calculated as the ratio of protein load (Ponceau) and slot intensity by antibody reaction.

\section{Protein preparation of maternal tissues and AGE detection by slot blot analyses}

After flushing out the blastocysts, we dissected the uterine tissue. Protein isolation was carried out either with the entire uteri or with separated endometria. For the latter, the endometrium was scraped mechanically from the myometrium using sharp scalpels. Grinded uteri and scraped endometria were mixed with RIPA and homogenized with precellys (Peqlab, Erlangen, Germany). Slot blot analyses were performed in the same way as for blastocysts. AGE accumulation in blood was determined using EDTA-plasma. Slot blot analysis with uterine proteins was performed in the same way as for blastocysts.

\section{Immunohistochemical localization of AGEs in blastocysts}

The immunohistochemical analysis was performed with single blastocysts as described previously (Schindler et al. 2014). Embryonic discs were incubated with mouse MABs against $\mathrm{CML}$, argpyrimidine, and pentosidine (1:100, Biologo). The nuclei were counterstained with hematoxylin. Embryonic discs were assessed using a light microscope (BZ 8100E, Keyence, Neu-Isenburg, Germany). The specificity of immunostaining of the secondary antibody reaction was proven by the absence of signals in sections processed after omission of the primary antibody.

\section{Immunohistochemical localization of AGEs in ovary and uterus}

Ovarian and uterine tissues were fixed in Bouin's solution, embedded in paraffin, and sectioned at $5 \mu \mathrm{m}$. Sections were mounted on silanized slides and deparaffinized at $60{ }^{\circ} \mathrm{C}$ overnight. Later, sections were rehydrated through a series of graded alcohols. Endogenous peroxidases were inhibited by incubating the slides with $3 \% \mathrm{H}_{2} \mathrm{O}_{2}$ in methanol. After blocking in $10 \%$ goat serum for at least $1 \mathrm{~h}$, the sections were incubated with the mouse $\mathrm{MABs}$ against $\mathrm{CML}$, argpyrimidine, or pentosidine $(1: 100$, Biologo $)$ at $4{ }^{\circ} \mathrm{C}$ overnight. Samples were washed with TBS-T and incubated with the HRPconjugated secondary goat anti-mouse IgG (Dako, Hamburg, Germany). The AGE-modified proteins were visualized by the peroxidase-diaminobenzidine reaction. The nuclei were counterstained with hematoxylin. Analysis was performed as described for blastocysts.

\section{Quantification of AGER mRNA in the rabbit blastocyst}

mRNA of single blastocysts was extracted using Dynabeads Oligo (dT) 25 (Invitrogen) and subsequently used for cDNA synthesis. The nucleotide sequence for rabbit AGER was determined using human primers for amplification of rabbit lung cDNA. The obtained rabbit AGER primers are as follows: sense, GCTACTGCTCCACCTTCTGG and antisense, GCAGTCAGAGCTGATGGTGA (ref. LOC100343142). The amount of AGER transcripts was determined by real-time quantitative PCR (RT-qPCR) using the Applied Biosystems StepOnePlus System (Applied Biosystems). The entire protocol for mRNA quantification and RT-qPCR has been described previously (Schindler et al. 2013).

\section{AGE fluorescence in the blastocyst cavity fluid}

To obtain the blastocyst cavity fluid (BCF), single blastocysts were washed twice with ice-cold PBS and placed on a Petri dish. The remaining PBS was removed and the blastocyst was punctured using a syringe. The escaping BCF was taken in an Eppendorf tube and stored at $-80^{\circ} \mathrm{C}$. The AGE fluorescence was determined in BCF using a Synergy MX 200 microplate reader (BioTek, Bad Friedrichshall, Germany). Then, $3 \mu \mathrm{l}$ of the undiluted BCF were analyzed in a black Take 3 Micro-Volume Plate (BioTek). PBS was used as a control. Fluorescence emission spectra were recorded at excitation wavelengths of 330 and $360 \mathrm{~nm}$. The maximum emission for the tested excitation wavelengths were found at 405 and $440 \mathrm{~nm}$ respectively.

\section{CML quantification in the BCF by HPLC/mass spectrometry}

CML was synthesized according to the literature (Glomb \& Monnier 1995). The identity of the reference compound was verified by nuclear magnetic resonance experiments. Furthermore, the elemental composition was confirmed by accurate mass determination. Up to seven BCF of at least two animals were pooled. The pooled BCF was diluted 1:10 with ultrapure water. The HPLC apparatus (Jasco, Gross-Umstadt, Germany) consisted of a pump (PU-2080 Plus) with a degasser (LG-2080-02) and a quaternary gradient mixer (LG-2080-04), a column oven (Jasco Jetstream II), and an Autosampler (AS-2057 Plus). Chromatographic separations were performed on a stainless steel column packed with RP-18 material (VYDAC CRT, no. 218TP54, 250× $4.6 \mathrm{~mm}, \mathrm{RP} 18,5 \mu \mathrm{m}$, Hesperia, CA, USA) using a flow rate of $1.0 \mathrm{ml} / \mathrm{min}$. The mobile phase used was water (solvent $A$ ) and methanol/water $(7: 3(\mathrm{v} / \mathrm{v})$, solvent $B)$. To both solvents (A and B), $1.2 \mathrm{ml} / \mathrm{l}$ heptafluorobutyric acid was added. Analysis was 
performed at $35{ }^{\circ} \mathrm{C}$ column temperature using isocratic elution at $98 \%$ of $\mathrm{A} / 2 \%$ of solvent $\mathrm{B}$. Mass spectrometric detection was conducted on a API 4000 Q Trap LC/mass spectrometry (MS/MS) system (AB Sciex, Darmstadt, Germany) equipped with a turbo ionspray source using electrospray ionization in the positive mode: sprayer capillary voltage, $2.5 \mathrm{kV}$; nebulizing gas flow, $50 \mathrm{ml} / \mathrm{min}$; heating gas, $60 \mathrm{ml} / \mathrm{min}$ at $550{ }^{\circ} \mathrm{C}$; and curtain gas, $40 \mathrm{ml} / \mathrm{min}$. The multiple reaction monitoring mode was used, utilizing collision-induced dissociation of the protonated molecule with compound-specific orifice potential $(50 \mathrm{~V})$ and fragment-specific collision energies (CEs). CML ( $\mathrm{m} / \mathrm{z} 205.1 \rightarrow$ 130.2 (CE 17), 84.1 (CE 46), and 159.1 (CE 15)) was detected at the retention time of $t_{\mathrm{R}}=6.0 \mathrm{~min}$.

Quantification was performed by the standard addition method. Briefly, increasing concentrations of an authentic reference compound by factors of $0.5,1,2$, and $3 \times$ the concentration of the analyte in the sample were added to separate aliquots of the sample after workup procedure. The aliquots were analyzed, and a regression of response vs concentration was used to determine the concentration of the analyte in the sample. Calibration using this method resolves potential matrix interferences.

All samples were analyzed in a single batch to exclude interassay variations. Intra-assay coefficient of variation values $(\mathrm{CV}=9 \%$ ) were determined by repeated analyses of a BCF sample $(n=5)$. In addition, the limit of detection $(\mathrm{LOD}=$ $4.8 \mathrm{pmol} / \mathrm{ml}$ ) and the limit of quantification $(\mathrm{LOQ}=$ $14.5 \mathrm{pmol} / \mathrm{ml}$ ) with all steps of the analysis included were estimated according to the German standard method DIN 32645: 2008-11 $(n=5$, confidence level $P=0.95$, and $k=3)$.

\section{Determination of glyoxal and methylglyoxal in plasma and blastocysts}

The quantification of glyoxal (GO) and methylglyoxal (MGO) was achieved mainly as described by Espinosa-Mansilla et al. (2007). Standard curves of GO and MGO (40\% aqueous solution, Sigma-Aldrich) were obtained by preparing serial dilution of GO and MGO (2700, 900, 300, 100, and 0 nM) in HPLC-grade water (Millipore). The rabbit plasma proteins and cell lysate proteins of the embryos were precipitated using trifluoroacetic acid (1/10 of the sample volume). After $10 \mathrm{~min}$ of incubation on ice, the samples were centrifuged at $13000 \mathrm{~g}$ for $10 \mathrm{~min}$. To $100 \mu \mathrm{l}$ of the supernatant, HPLC-grade water was added (final volume, $1 \mathrm{ml}$ ) followed by the addition of $0.125 \mathrm{ml}$ ammonium chloride (0.5 M; pH 10.0) and $2.5 \mathrm{ml}$ of 5,6 diamino-2,4-hydroxypyrimidine sulfate $(0.75 \mathrm{mM})$. The mixture was incubated for $90 \mathrm{~min}$ at $60^{\circ} \mathrm{C}$ with constant shaking. Subsequently, citrate buffer $(10 \mathrm{mM}$; $\mathrm{pH} 6.0)$ was added to a final volume of $25 \mathrm{ml}$. For the analysis, $10 \mu \mathrm{l}$ of the samples were injected (ZORBAX, Eclipse XDB-C18 4.6×150 mm 5-micron column; Agilent, Oberhaching, Germany) and then separated by gradient elution with solvents $A$ ( $3 \%$ acetonitrile) and B $(97 \%$ citrate buffer $)$ at a flow rate of $0.8 \mathrm{ml} / \mathrm{min}$.

\section{Statistical analysis}

To obtain statistically funded data, we repeated the animal experiment at least three times $(n=3)$. In each animal experiment, we had nine diabetic and six healthy rabbits. We pooled tissue samples and blastocysts from each individual experiment from at least three animals. Levels of significance between groups were calculated using Student's $t$-test after proving normal distribution (SigmaPlot v. 11.0). The MannWhitney $U$ rank sum test was used when a normal distribution was not guaranteed. Data are expressed as mean \pm S.E.M. The levels of statistical significance were $* P<0.05$, **P $P 0.01$, and $* * * P<0.001$.

\section{Results}

\section{Determination of $\alpha$-dicarbonyls and AGEs in the plasma of female rabbits with type $1 \mathrm{DM}$}

As the majority of AGEs in vivo appear to be formed from $\boldsymbol{\alpha}$-dicarbonyls (Brownlee 1995, Rabbani \& Thornalley 2012), we measured the plasma level of GO and MGO by HPLC. The AGE precursor MGO was not altered, whereas GO (control $398 \pm 31 \mathrm{nM}$ and diabetic $522 \pm 59 \mathrm{nM}$ ) was tendentially enhanced (Fig. 2A). To determine the AGE status of the diabetic rabbits, we investigated various AGEs by slot blot analysis with specific antibodies against pentosidine, $\mathrm{CML}$, and argpyrimidine respectively. All of the analyzed protein modifications showed a considerable increase in the plasma probes of diabetic rabbits (Fig. 2B and C).

\section{Determination of AGE modifications in the reproductive tract of female rabbits with type 1 DM}

The constitution of the uterus tissue is crucial for the course of pregnancy. The endometrium, a dynamic mucosa adjacent to the myometrium of the uterus, is important for the implantation process. Argpyrimidine,
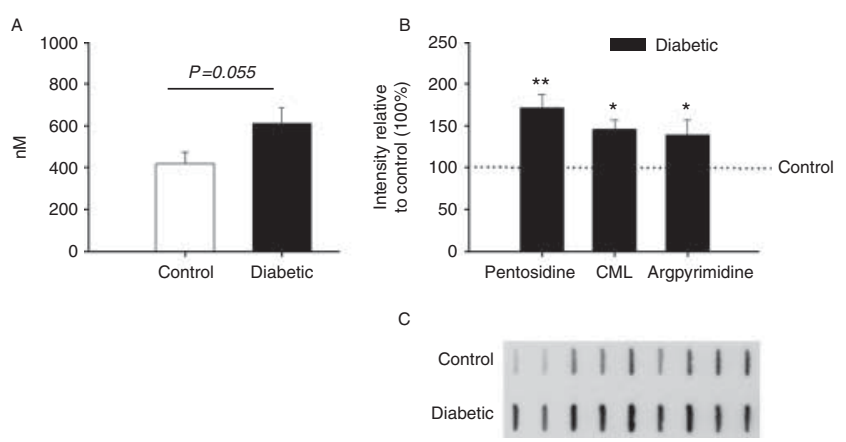

Figure $2(\mathrm{~A})$ Concentration of glyoxal (GO) in diabetic and non-diabetic rabbits. GO was quantified by HPLC (mean \pm S.E.M.; $N=3, n=3$; $P=$ as indicated). (B) Relative amount of protein-bound pentosidine, $N^{\varepsilon}$-carboxymethyllysine $(\mathrm{CML})$, and argpyrimidine in the plasma of rabbits after being diabetic for $\sim 2$ weeks compared with the nondiabetic control (set 100\%). The quantification was performed by slot blot analysis (mean \pm S.E.M.; $N=3, n=9 ; * P<0.05$ and ${ }^{* *} P<0.01$ ). The AGE amount is related to the protein load (Ponceau $S$ staining). (C) A representative slot blot is shown for pentosidine. 


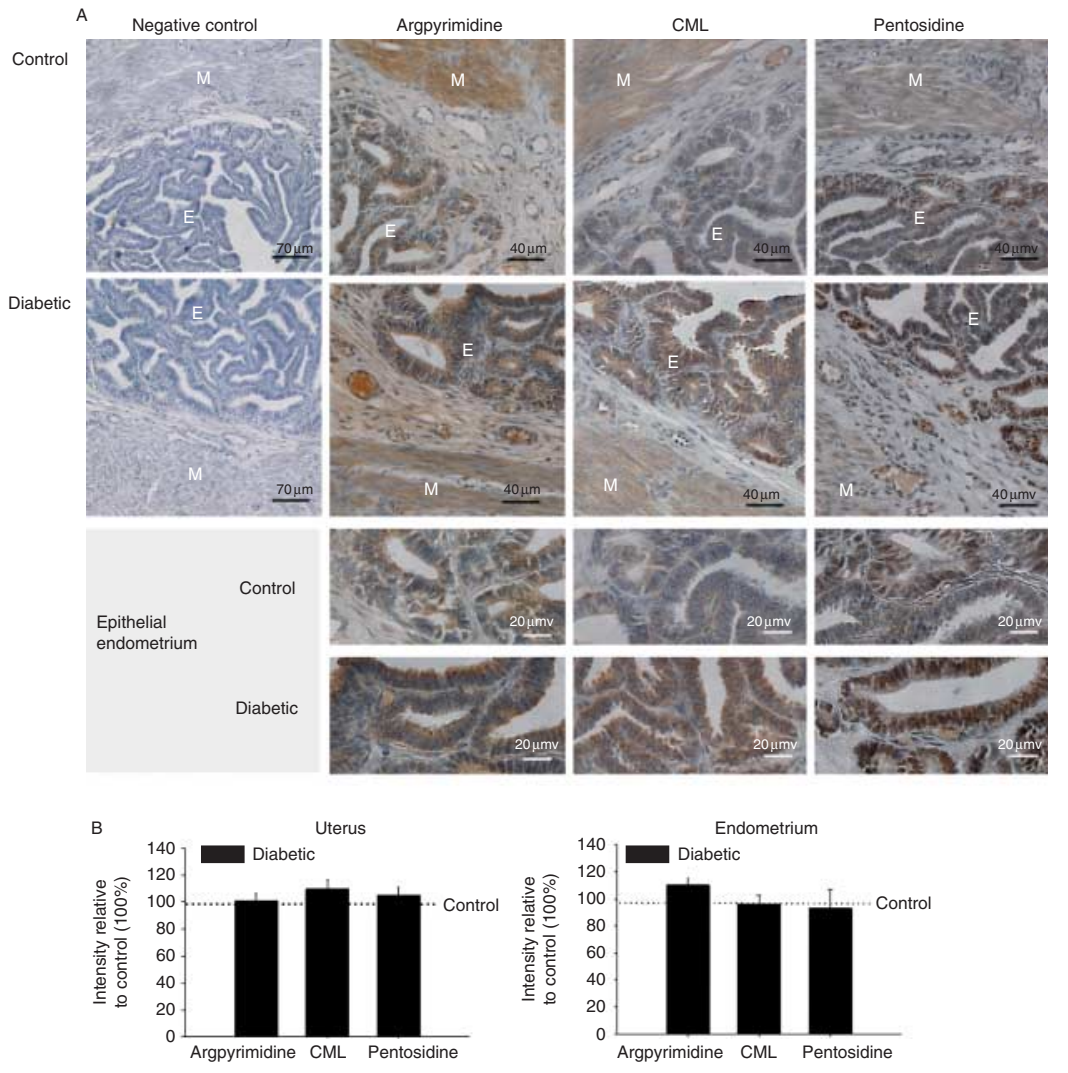

Figure 3 (A) Immunohistochemical analysis of argpyrimidine, $N^{\varepsilon}$-carboxymethyllysine $(\mathrm{CML})$, and pentosidine in the pregnant uterus of rabbits with type 1 diabetes mellitus and in healthy controls. The AGE-modified proteins were visualized by the peroxidase-diaminobenzidine reaction (brown color). The nucleus was counterstained with hematoxylin (blue colour). The negative control is the control reaction of the HRP-conjugated secondary goat antimouse IgG without a primary antibody. CML and argpyrimidine show an exclusive cytosolic staining, whereas pentosidine is localized to both the cytosol and the nucleus. The epithelial endometrium (E) of diabetic rabbits shows a stronger staining, whereas the staining of the myometrium $(M)$ seems to be unchanged. (B) Relative amounts of protein-bound argpyrimidine, $\mathrm{CML}$, and pentosidine in the entire uterus and the separated endometrium from diabetic and healthy rabbits measured by slot blot analysis (mean \pm S.E.M.; $N=3, n=9$ ). The amounts of AGE are related to the protein load (Ponceau $\mathrm{S}$ staining).
$\mathrm{CML}$, and pentosidine are present in the endometrium and myometrium. AGEs are localized to smooth muscle cells, not only in the myometrium but also in the endothelium of vessels. In the endometrium, CML and pentosidine are exclusively present in the epithelium; argpyrimidine is also slightly present in the stroma. CML and argpyrimidine were mainly localized to the cytoplasm. Pentosidine showed a cytosolic staining and stained nuclei. CML, pentosidine, and argpyrimidine showed a strongly stained endometrial epithelium in diabetic rabbits (Fig. 3A).

Slot blot analyses revealed no differences in proteinbound $\mathrm{CML}$, pentosidine, and argpyrimidine between diabetic and normoglycemic rabbits for the entire uterus and for the endometrium in particular (Fig. 3B).

Immunohistochemical staining of the ovary revealed no differences between normoglycemic and diabetic females. Figure 4 shows the AGE distribution in the ovary from normoglycemic controls. All determined AGEs were detectable in the ovary. CML and argpyrimidine showed an exclusive cytosolic staining, whereas pentosidine was localized to both the cytoplasm and nuclei. The oocyte showed positive staining for $\mathrm{CML}$, pentosidine, and argpyrimidine in the cytoplasm, but not in the nucleus in the investigated follicle stages (primary, secondary, and tertiary follicle).

\section{Determination of AGE modifications in 6-day-old rabbit blastocysts developed under diabetic conditions}

Immunohistochemical detection of pentosidine, CML, and argpyrimidine showed strong staining in the embryoblast (EB) and well-stained trophoblast (TB) cells (Fig. 5A). All detected AGEs were exclusively present in the cytoplasm. Slot blot analysis revealed a significantly higher level of protein-bound $\mathrm{CML}$ in blastocysts from diabetic mothers (Fig. 5B). Similarly, argpyrimidine level was tendentially increased. The detection of the reactive $\alpha$-dicarbonyls MGO showed no differences between blastocysts from diabetic and normoglycemic rabbits (Fig. 5C). GO was under the detection limit.

The BCF is known to be an important reservoir for nutrients during preimplantation. We used the fluorescent properties of AGEs to determine AGE accumulation in the BCF. Specific peaks for the known AGE fluorescence with excitation and emission at wavelengths of 330/405 and 360/440 nm, respectively, were detectable. Both were significantly increased in the BCF of blastocysts developed under diabetic conditions (Fig. 6A). The protein content of the BCF was equal in both groups with $0.43 \pm 0.012 \mu \mathrm{g} / \mu \mathrm{l}$. Besides fluorescent AGEs, the non-fluorescent CML as a free adduct was identified by HPLC/MS in the BCF. The quantification of 


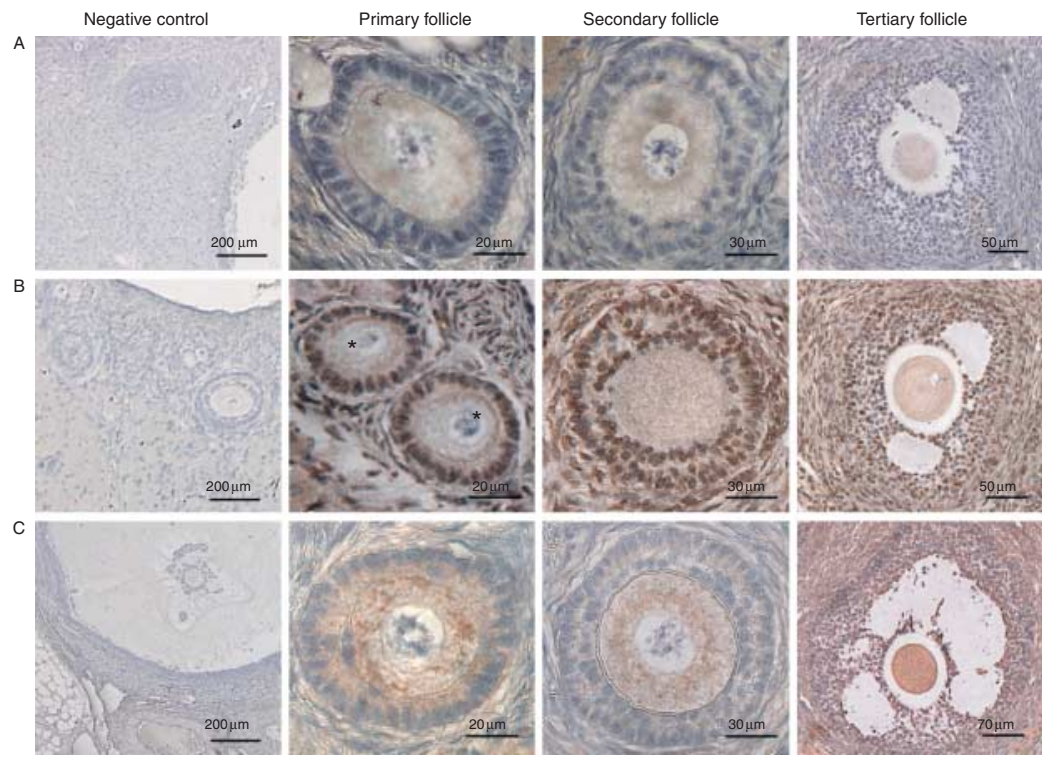

Figure 4 Immunohistochemical analysis of $N^{E}$-carboxymethyllysine (A), pentosidine (B), and argpyrimidine $(\mathrm{C})$ in the ovary of healthy rabbits. Follicle growth was stimulated by s.c. injection of pregnant mare's serum gonadotropin. The AGEmodified proteins were visualized by the peroxidasediaminobenzidine reaction (brown color). The nuclei were counterstained with hematoxylin (blue color). The negative control is the control reaction of the HRP-conjugated secondary goat anti-mouse IgG without a primary antibody. CML and argpyrimidine show an exclusive cytosolic staining, whereas pentosidine was localized to both the cytoplasm and the nuclei, except for nuclei of the oocytes*.
CML showed a higher amount of soluble CML in the BCF of blastocysts from diabetic mothers with $0.26 \pm$ $0.05 \mu \mathrm{mol} / \mathrm{l}$ compared with controls with $0.18 \pm$ $0.02 \mu \mathrm{mol} / \mathrm{l}$ (Fig. 6B).

\section{AGER mRNA amount in rabbit blastocysts}

AGER mRNA was detectable from the early blastocyst stage (day 4 p.c.) onwards (Ott et al. 2014). At day 6 p.c., the amount of $A G E R$ mRNA was significantly increased under diabetic conditions (Fig. 7).

\section{Discussion}

An intrauterine exposure to hyperglycemia has been shown to cause alterations in pre- and postnatal growth patterns. The underlying metabolic disorder may predispose offspring to develop metabolic diseases in later life (Silveira et al. 2007). Several animal studies demonstrated a developmental delay for embryos recovered from diabetic mothers (Giavini et al. 1986, Moley et al. 1991, Ramin et al. 2010). Our study provides new insights into the effects of a maternal DM during the preimplantation period by analyzing the AGE formation in both, the mother and the developing embryo. Thus far, AGE formation is mostly associated with aging and diseases. By contrast, Ling et al. (2001) had already reported AGE modifications in fetal rats from day 10 p.c. onwards. A recently published study has revealed a high rate of glycated and oxidized proteins in undifferentiated mouse embryonic stem cells (ESCs) and in mouse blastocysts at day 3.5 p.c. HSPA8 (HSC70) was identified as the major protein modified by $\mathrm{CML}$ in undifferentiated mouse ESCs (Hernebring et al. 2006). Similar to the findings of our study on day 6 rabbit blastocysts, AGE-modified proteins were mainly present in the EB, and strongly stained cells were also found in the TB (Fig. 5A). The protein modifications by pentosidine, $\mathrm{CML}$, and argpyrimidine were almost exclusively observed in the cytoplasm.

It is known that AGEs accumulate intracellularly (Goldin et al. 2006). Besides the physiological appearance of AGEs in preimplantation embryos, we observed pathological AGE accumulations in blastocysts from diabetic mothers. Blastocysts are obviously susceptible for AGE formation while growing up in a diabetic uterine milieu. A 6-day-old rabbit blastocyst developed in a diabetic uterine milieu showed tendentially more AGEs intracellularly and in the BCF compared with age- and stage-matched control blastocysts (Figs 5 and 6). Proteinbound $\mathrm{CML}$ and argpyrimidine levels were elevated, whereas protein-bound pentosidine was unchanged. $\mathrm{CML}$ and argpyrimidine are AGEs resulting from reactions of $\alpha$-dicarbonyls (GO and $\mathrm{MGO}$ ) and amino groups that are known to be highly reactive. Although glucose and fructose are present in significant concentrations in uterine secretions, the fact that they react slowly with proteins to form AGEs must be taken into consideration. Pentosidine is sourced mostly from ribose but also from glucose (Dyer et al. 1991, Grandhee \& Monnier 1991). Previous investigations had demonstrated an unchanged glucose uptake in rabbit blastocysts developed under normoglycemic and diabetic conditions (Schindler et al. 2013). These findings might explain the unchanged protein-bound pentosidine concentration. The intracellular glucose concentration has not been determined so far. We found measurable, but unaltered, concentrations of MGO in blastocysts 


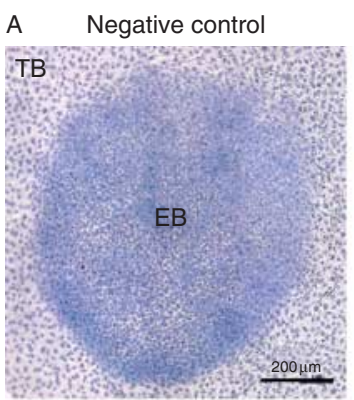

CML
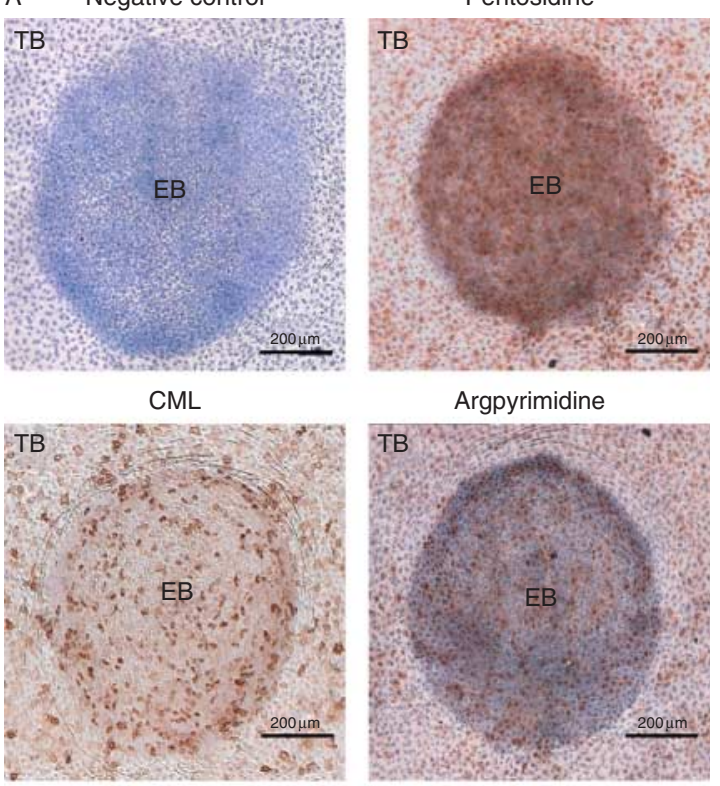

Argpyrimidine
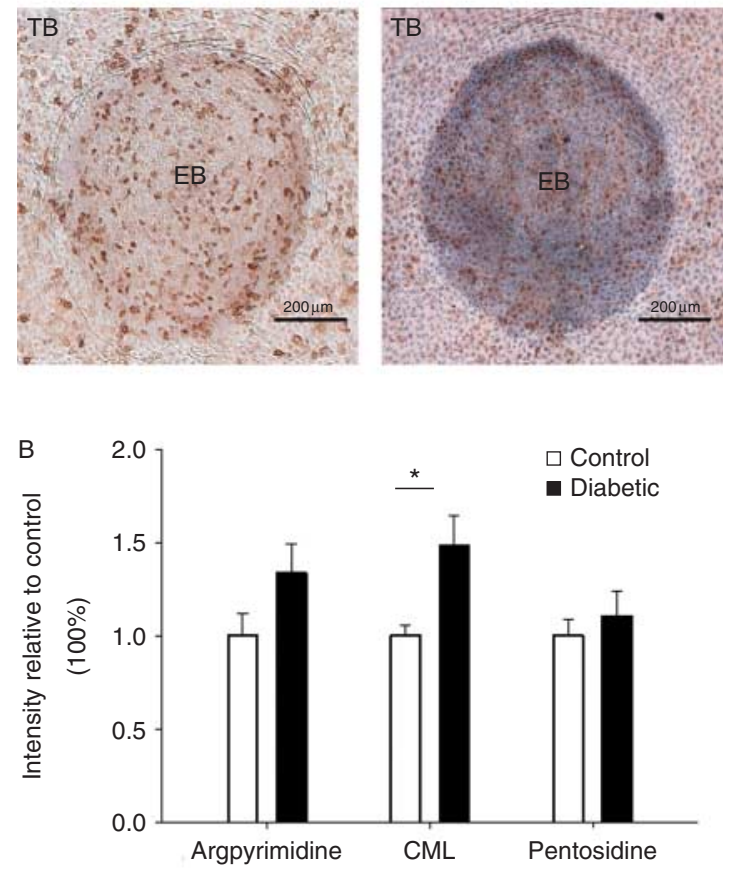

C

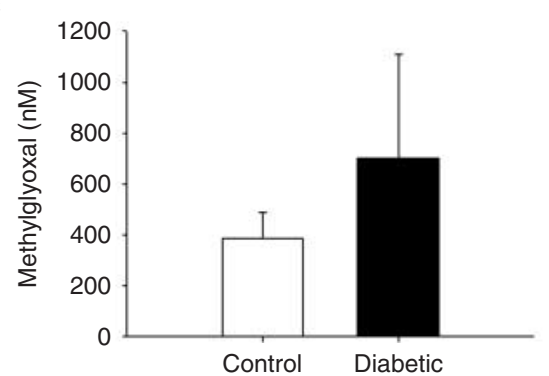

Figure 5 (A) Immunohistochemical analysis of argpyrimidine,

$N^{\varepsilon}$-carboxymethyllysine (CML), and pentosidine in embryoblast $(\mathrm{EB})$ and trophoblast (TB) cells of 6-day-old rabbit blastocysts. The AGE-modified proteins were visualized by the peroxidase-diaminobenzidine reaction (brown color). The used antibodies show an exclusive cytosolic staining. The EB has tendentially more AGE modifications than the TB. The nucleus was counterstained with hematoxylin (blue colour). The negative control is the control reaction of the HRP-conjugated secondary goat anti-mouse IgG without a primary antibody. (B) Relative amounts of protein-bound argpyrimidine, CML, and pentosidine in 6-day-old rabbit blastocysts from diabetic and healthy (control) rabbits analyzed by slot blot analysis (mean \pm S.E.M.; $N=6, n=8-10 ; * P<0.05$ ). The amount of AGE is related to the protein load (Ponceau $\mathrm{S}$ staining). (C) Methylglyoxal quantification in 6-day-old rabbit blastocyst by HPLC (mean \pm S.E.M.; $N=3, n=8-10$ ). from diabetic and normoglycemic rabbits (Fig. 5C). The quantification of $\mathrm{GO}$ in blastocysts failed at the detection limit of $300 \mathrm{nM}$. Recent estimates of the cellular concentrations are 1-5 $\mu \mathrm{M}$ for $\mathrm{MGO}$ and $0.1-1 \mu \mathrm{M}$ for $\mathrm{GO}$ (Dobler et al. 2006). Formation of MGO arises from a decreased activity of the reductive pentose phosphate pathway and formation of GO arises from lipid peroxidation (Fu et al. 1996, Januszewski et al. 2003, Thornalley \& Rabbani 2009). We have new evidence that the lipid metabolism is altered in the rabbit blastocyst in case of a maternal DM. Besides noticeable lipid accumulations, the transport protein for fatty acids and other lipophilic substances, fatty acid-binding protein, is upregulated (Schindler et al. 2014). The two pathways - altered fatty acid metabolism and AGE formation - may interact and contribute to specific aspects of maternal subfertility in DM. In the rabbit model, maternal DM is associated with a reduced ovulation rate and lower number of blastocysts. Blastocyst development is retarded (Ramin et al. 2010). A recently published study has demonstrated that in ART patients an increased AGE concentration in human follicular fluid is associated with diminished follicle growth, a lower fertilization rate, and delayed embryo development (Jinno et al. 2011).

A major reason for AGE-mediated damage is the activation of RAGEs (Bierhaus et al. 2005, Nass et al. 2007, Berbaum et al. 2008, Rouhiainen et al. 2013). RAGE-ligand interaction leads to an increase in the expression of AGER. This type of positive feedback loop results in prolonged NFKB activation (Bierhaus \& Nawroth 2009, Fritz 2011). In our study, we found a similar positive correlation between AGE accumulation and an increased $A G E R$ mRNA expression in blastocysts from diabetic mothers, confirming the view that AGE-RAGE interaction leads to an upregulation of RAGEs. This finding could be a proof for an active AGE-RAGE system in the blastocyst, which may negatively affect the embryo quality in diabetic mothers.

From which source the observed AGEs in the early embryo originate is uncertain. As AGE formation, especially due to glucose reactions, is an exceedingly
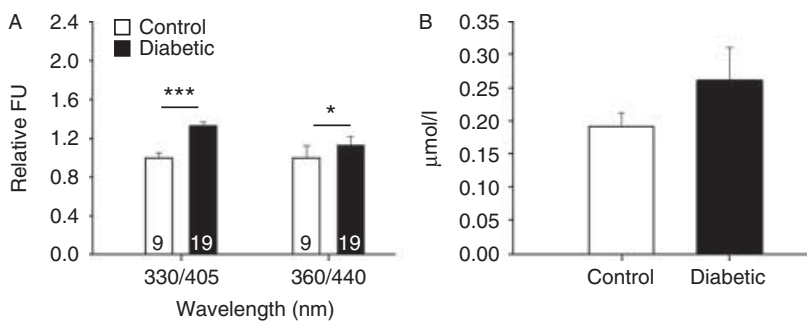

Figure 6 (A) Relative AGE fluorescence in the blastocyst cavity fluid (BCF) of blastocysts from diabetic and control rabbits (mean \pm s.E.M., $N=3, n=$ as indicated; $* P<0.05$ and ${ }^{* * *} P<0.001$ ). (B) The free AGE adduct $N^{\varepsilon}$-carboxymethyllysine $(\mathrm{CML})$ in the BCF was quantified by HPLC/mass spectrometry $(N=4, n=15-18)$. 


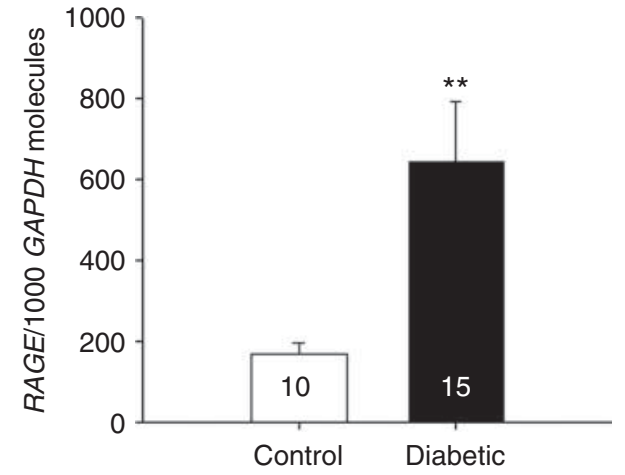

Figure 7 RAGE mRNA amount in 6-day-old blastocysts from diabetic and control rabbits. RAGE mRNA was related to the amount of GAPDH mRNA molecules per blastocyst (mean \pm s.E.M.; $N=6, n=$ as indicated, $* * P<0.01)$.

slow process and the degradation of AGEs in vivo is negligible, it can be assumed that AGEs may descent from germ cells. Matsumine et al. (2008) have demonstrated increased levels of pentosidine in the primordial, primary, and atretic follicles in premenopausal women. The reduced fertility and reduction in the follicle quality during aging are supposed to be, besides other reasons, due to AGE accumulation (Tatone \& Amicarelli 2013). Our rabbit model confirms the presence of AGEs in oocytes (Fig. 4). As the experimentally induced type 1 DM had no effect on the AGE concentration in oocytes, it is unlikely that the accumulated AGEs in diabetic blastocysts are of oocyte origin in our model. However, it is likely that AGEs found in the oocyte might be still present in the developing embryo. This view may be relevant to women of older age, as AGE accumulation takes place for a longer term in this case, and to women with a long-term poorly controlled DM.

The increased CML concentration in the diabetic blastocyst (Fig. 5B) was additionally reflected by increased CML concentrations in the BCF (Fig. 6B). Furthermore, diabetic mothers showed increased amounts of CML in the plasma (Fig. 2B) and, through immunohistochemical detection, in the endometrium (Fig. 3A). The disparity between the results of immunohistochemistry and slot blot analysis in uterine tissue (Fig. 3) may be caused by the broad spectrum of AGE modification in tissues. The used antibodies are able to detect, besides protein-bound modifications, free AGEs. It is known that the non-enzymatic reaction between reducing sugars and amino groups also affects lipids and nucleic acids. The immunohistochemical method might capture more AGE modifications than slot blot analysis that detects only protein-bound AGEs. As CML level is increases in both, mother and blastocyst, it is possible that the maternally formed CML are transferred to the embryo. Little is known about the transport mechanism of AGEs. Experiments with Caco-2 cells showed a low transepithelial flux of CML. However, there was no measurable active transport for $\mathrm{CML}$ across the epithelial monolayer, neither via PEPT1 (SLC15A1) nor by carriers for neutral amino acids. The observation led to the conclusion that the transport is based on simple diffusion (Grunwald et al. 2006). Further studies are necessary to clarify this hypothesis.

For the first time, we demonstrate that one consequence of maternal DM is AGE formation in preimplantation embryos. AGEs do accumulate in blastocysts if the maternal DM is poorly controlled. Although our results do not provide a causative mechanism between embryo toxicity and DM, it is likely that AGEs play a role as stimuli for activating intracellular stress pathways and, additionally, do affect the molecular function of intracellular proteins. It is known that even moderate changes in the preimplantation environment can adversely affect the pre- and postnatal phenotypes (Fleming et al. 2004, Sinclair \& Singh 2007). A clear consequence of these findings is the necessity for a strict control of maternal blood glucose levels during pregnancy from the day of conception onwards.

\section{Declaration of interest}

The authors declare that there is no conflict of interest that could be perceived as prejudicing the impartiality of the research reported.

\section{Funding}

This work was supported by the EU (FP-7 Epihealth Nr 278418) and the Wilhelm Roux Programme of the MLU Faculty of Medicine.

\section{Acknowledgements}

The authors thank Michaela Kirstein and Sabine Schrötter for their excellent technical assistance.

\section{References}

Aberg A, Westbom L \& Källén B 2001 Congenital malformations among infants whose mothers had gestational diabetes or preexisting diabetes. Early Human Development 61 85-95. (doi:10.1016/S0378-3782(00)00125-0)

Ahmed N \& Thornalley PJ 2007 Advanced glycation endproducts: what is their relevance to diabetic complications? Diabetes, Obesity \& Metabolism 9 233-245. (doi:10.1111/j.1463-1326.2006.00595.x)

American Diabetes Association 2013 Diagnosis and classification of diabetes mellitus. Diabetes Care 36 (Suppl 1) S67-S74. (doi:10.2337/ dc13-s067)

Berbaum K, Shanmugam K, Stuchbury G, Wiede F, Körner H \& Münch G 2008 Induction of novel cytokines and chemokines by advanced glycation endproducts determined with a cytometric bead array. Cytokine 41 198-203. (doi:10.1016/j.cyto.2007.11.012)

Bierhaus A \& Nawroth PP 2009 Multiple levels of regulation determine the role of the receptor for AGE (RAGE) as common soil in inflammation, immune responses and diabetes mellitus and its complications. Diabetologia 52 2251-2263. (doi:10.1007/s00125-009-1458-9) 
Bierhaus A, Humpert PM, Morcos M, Wendt T, Chavakis T, Arnold B, Stern DM \& Nawroth PP 2005 Understanding RAGE, the receptor for advanced glycation end products. Journal of Molecular Medicine $\mathbf{8 3}$ 876-886. (doi:10.1007/s00109-005-0688-7)

Bos DC, de Ranitz-Greven WL \& de Valk HW 2011 Advanced glycation end products, measured as skin autofluorescence and diabetes complications: a systematic review. Diabetes Technology \& Therapeutics 13 773-779. (doi:10.1089/dia.2011.0034)

Boutzios G, Livadas S, Piperi C, Vitoratos N, Adamopoulos C, Hassiakos D, lavazzo C \& Diamanti-Kandarakis E 2013 Polycystic ovary syndrome offspring display increased oxidative stress markers comparable to gestational diabetes offspring. Fertility and Sterility 99 943-950. (doi:10.1016/j.fertnstert.2012.10.050)

Brownlee M 1995 Advanced protein glycosylation in diabetes and aging. Annual Review of Medicine 46 223-234. (doi:10.1146/annurev.med.46.1.223)

Buongiorno AM, Morelli S, Sagratella E, Castaldo P, Di Virgilio A, Maroccia E, Ricciardi G, Sciullo E, Cardellini G, Fallucca F et al. 1997 Levels of advanced glycosylation end-products (AGE) in sera of pregnant diabetic women: comparison between type 1, type 2 and gestational diabetes mellitus. Annali dell'Istituto Superiore di Sanità 33 375-378.

Carubelli R, Schneider JE Jr, Pye QN \& Floyd RA 1995 Cytotoxic effects of autoxidative glycation. Free Radical Biology \& Medicine 18 265-269. (doi:10.1016/0891-5849(94)E0134-5)

Combs CA \& Kitzmiller JL 1991 Spontaneous abortion and congenital malformations in diabetes. Baillière's Clinical Obstetrics and Gynaecology 5 315-331. (doi:10.1016/S0950-3552(05)80100-2)

Corrigan N, Brazil DP \& McAuliffe F 2009 Fetal cardiac effects of maternal hyperglycemia during pregnancy. Birth Defects Research. Part A, Clinical and Molecular Teratology 85 523-530. (doi:10.1002/bdra.20567)

Dobler D, Ahmed N, Song L, Eboigbodin KE \& Thornalley PJ 2006 Increased dicarbonyl metabolism in endothelial cells in hyperglycemia induces anoikis and impairs angiogenesis by RGD and GFOGER motif modification. Diabetes 55 1961-1969. (doi:10.2337/db05-1634)

Dyer DG, Blackledge JA, Thorpe SR \& Baynes JW 1991 Formation of pentosidine during nonenzymatic browning of proteins by glucose. Identification of glucose and other carbohydrates as possible precursors of pentosidine in vivo. Journal of Biological Chemistry 266 11654-11660.

Dyer DG, Dunn JA, Thorpe SR, Bailie KE, Lyons TJ, McCance DR \& Baynes JW 1993 Accumulation of Maillard reaction products in skin collagen in diabetes and aging. Journal of Clinical Investigation 91 2463-2469. (doi:10.1172/JCI116481)

Eriksson UJ, Borg LA, Cederberg J, Nordstrand H, Simán CM, Wentzel C \& Wentzel P 2000 Pathogenesis of diabetes-induced congenital malformations. Upsala Journal of Medical Sciences 105 53-84.

Eriksson UJ, Cederberg J \& Wentzel P 2003 Congenital malformations in offspring of diabetic mothers - animal and human studies. Reviews in Endocrine \& Metabolic Disorders 4 79-93. (doi:10.1023/ A:1021879504372)

Espinosa-Mansilla A, Durán-Merás I, Cañada FC \& Márquez MP 2007 High-performance liquid chromatographic determination of glyoxal and methylglyoxal in urine by prederivatization to lumazinic rings using in serial fast scan fluorimetric and diode array detectors. Analytical Biochemistry 371 82-91. (doi:10.1016/j.ab.2007.07.028)

Fischer B, Mootz U, Denker HW, Lambertz M \& Beier HM 1991 The dynamic structure of rabbit blastocyst coverings. III. Transformation of coverings under non-physiological developmental conditions. Anatomy and Embryology 183 17-27. (doi:10.1007/BF00315639)

Fischer S, Santos AN, Thieme R, Ramin N \& Fischer B 2010 Adiponectin stimulates glucose uptake in rabbit blastocysts. Biology of Reproduction 83 859-865. (doi:10.1095/biolreprod.110.084665)

Fleming TP, Kwong WY, Porter R, Ursell E, Fesenko I, Wilkins A, Miller DJ, Watkins AJ \& Eckert JJ 2004 The embryo and its future. Biology of Reproduction 71 1046-1054. (doi:10.1095/biolreprod.104.030957)

Fritz G 2011 RAGE: a single receptor fits multiple ligands. Trends in Biochemical Sciences 36 625-632. (doi:10.1016/j.tibs.2011.08.008)

Fu MX, Requena JR, Jenkins AJ, Lyons TJ, Baynes JW \& Thorpe SR 1996 The advanced glycation end product, $N \varepsilon$-(carboxymethyl) lysine, is a product of both lipid peroxidation and glycoxidation reactions. Journal of Biological Chemistry 271 9982-9986. (doi:10.1074/jbc.271.33.19641)

Giavini E, Broccia ML, Prati M, Roversi GD \& Vismara C 1986 Effects of streptozotocin-induced diabetes on fetal development of the rat. Teratology 34 81-88. (doi:10.1002/tera.1420340111)
Glomb MA \& Monnier VM 1995 Mechanism of protein modification by glyoxal and glycolaldehyde, reactive intermediates of the Maillard reaction. Journal of Biological Chemistry 270 10017-10026. (doi:10. 1074/jbc.270.17.10017)

Goh S-Y \& Cooper ME 2008 Clinical review: The role of advanced glycation end products in progression and complications of diabetes. Journal of Clinical Endocrinology and Metabolism 93 1143-1152. (doi:10.1210/ jc.2007-1817)

Goldin A, Beckman JA, Schmidt AM \& Creager MA 2006 Advanced glycation end products sparking the development of diabetic vascular injury. Circulation 114 597-605. (doi:10.1161/CIRCULATIONAHA.106. 621854)

Grandhee SK \& Monnier VM 1991 Mechanism of formation of the Maillard protein cross-link pentosidine. Glucose, fructose, and ascorbate as pentosidine precursors. Journal of Biological Chemistry 266 11649-11653.

Greene MF 1999 Spontaneous abortions and major malformations in women with diabetes mellitus. Seminars in Reproductive Endocrinology 17 127-136. (doi:10.1055/s-2007-1016220)

Grunwald S, Krause R, Bruch M, Henle T \& Brandsch M 2006 Transepithelial flux of early and advanced glycation compounds across Caco-2 cell monolayers and their interaction with intestinal amino acid and peptide transport systems. British Journal of Nutrition 95 1221-1228. (doi:10.1079/BJN20061793)

Guosheng L, Hongmei S, Chuan N, Haiying L, Xiaopeng Z \& Xianqiong L 2009 The relationship of serum AGE levels in diabetic mothers with adverse fetal outcome. Journal of Perinatology 29 483-488. (doi:10. 1038/jp.2009.12)

Hernebring M, Brolén G, Aguilaniu H, Semb H \& Nyström T 2006 Elimination of damaged proteins during differentiation of embryonic stem cells. PNAS 103 7700-7705. (doi:10.1073/pnas.0510944103)

Herrler A, von Wolff M \& Beier HM 2002 Proteins in the extraembryonic matrix of preimplantation rabbit embryos. Anatomy and Embryology 206 49-55. (doi:10.1007/s00429-002-0270-9)

Januszewski AS, Alderson NL, Metz TO, Thorpe SR \& Baynes JW 2003 Role of lipids in chemical modification of proteins and development of complications in diabetes. Biochemical Society Transactions $\mathbf{3 1}$ 1413-1416. (doi:10.1042/BST0311413)

Jinno M, Takeuchi M, Watanabe A, Teruya K, Hirohama J, Eguchi N \& Miyazaki A 2011 Advanced glycation end-products accumulation compromises embryonic development and achievement of pregnancy by assisted reproductive technology. Human Reproduction 26 604-610. (doi:10.1093/humrep/deq388)

Lee AT \& Cerami A 1992 Role of glycation in aging. Annals of the New York Academy of Sciences 663 63-70. (doi:10.1111/j.1749-6632.1992. tb38649.x)

Ling X, Nagai R, Sakashita N, Takeya M, Horiuchi S \& Takahashi K 2001 Immunohistochemical distribution and quantitative biochemical detection of advanced glycation end products in fetal to adult rats and in rats with streptozotocin-induced diabetes. Laboratory Investigation $\mathbf{8 1}$ 845-861. (doi:10.1038/labinvest.3780294)

Matsumine M, Shibata N, Ishitani K, Kobayashi M \& Ohta H 2008 Pentosidine accumulation in human oocytes and their correlation to agerelated apoptosis. Acta Histochemica et Cytochemica 41 97-104. (doi:10.1267/ahc.08014)

Moley KH, Vaughn WK, DeCherney AH \& Diamond MP 1991 Effect of diabetes mellitus on mouse pre-implantation embryo development. Journal of Reproduction and Fertility 93 325-332. (doi:10.1530/jrf. 0.0930325)

Nass N, Bartling B, Navarrete Santos A, Scheubel RJ, Börgermann J, Silber RE \& Simm A 2007 Advanced glycation end products, diabetes and ageing. Zeitschrift für Gerontologie und Geriatrie 40 349-356. (doi:10.1007/s00391-007-0484-9)

Ortwerth BJ, James H, Simpson G \& Linetsky M 1998 The generation of superoxide anions in glycation reactions with sugars, osones, and 3-deoxyosones. Biochemical and Biophysical Research Communications 245 161-165. (doi:10.1006/bbrc.1998.8401)

Ott C, Jacobs K, Haucke E, Navarrete Santos A, Grune T \& Simm A 2014 Role of advanced glycation end products in cellular signaling. Redox Biology 2 411-429. (doi:10.1016/j.redox.2013.12.016)

Rabbani N \& Thornalley PJ 2012 Methylglyoxal, glyoxalase 1 and the dicarbonyl proteome. Amino Acids 42 1133-1142. (doi:10.1007/ s00726-010-0783-0) 
Ramin N, Thieme R, Fischer S, Schindler M, Schmidt T, Fischer B \& Navarrete Santos A 2010 Maternal diabetes impairs gastrulation and insulin and IGF-I receptor expression in rabbit blastocysts. Endocrinology 151 4158-4167. (doi:10.1210/en.2010-0187)

Rouhiainen A, Kuja-Panula J, Tumova S \& Rauvala H 2013 RAGE-mediated cell signaling. Methods in Molecular Biology 963 239-263. (doi:10. 1007/978-1-62703-230-8_15)

Schindler M, Fischer S, Thieme R, Fischer B \& Santos AN 2013 cAMP-responsive element binding protein: a vital link in embryonic hormonal adaptation. Endocrinology 154 2208-2221. (doi:10.1210/ en.2012-2096)

Schindler M, Pendzialek M, Navarrete Santos A, Plösch T, Seyring S, Gürke J, Haucke E, Knelangen JM, Fischer B \& Santos AN 2014 Maternal diabetes leads to unphysiological high lipid accumulation in rabbit preimplantation embryos. Endocrinology 155 1498-1509. (doi:10.1210/ en.2013-1760)

Sell DR, Nagaraj RH, Grandhee SK, Odetti P, Lapolla A, Fogarty J \& Monnier VM 1991 Pentosidine: a molecular marker for the cumulative damage to proteins in diabetes, aging, and uremia. Diabetes/Metabolism Reviews 7 239-251. (doi:10.1002/dmr. 5610070404)
Silveira PP, Portella AK, Goldani MZ \& Barbieri MA 2007 Developmental origins of health and disease (DOHaD). Jornal de Pediatria 83 494-504. (doi:10.2223/JPED.1728)

Sinclair KD \& Singh R 2007 Modelling the developmental origins of health and disease in the early embryo. Theriogenology 67 43-53. (doi:10. 1016/j.theriogenology.2006.09.017)

Tatone C \& Amicarelli F 2013 The aging ovary - the poor granulosa cells. Fertility and Sterility 99 12-17. (doi:10.1016/j.fertnstert.2012.11.029)

Thornalley PJ \& Rabbani N 2009 Highlights and hotspots of protein glycation in end-stage renal disease. Seminars in Dialysis 22 400-404. (doi:10.1111/j.1525-139X.2009.00589.x)

Watkins A, Papenbrock T \& Fleming T 2008 The preimplantation embryo: handle with care. Seminars in Reproductive Medicine 26 175-185. (doi:10.1055/s-2008-1042956)

Received 17 March 2014

First decision 3 April 2014

Revised manuscript received 15 April 2014

Accepted 12 May 2014 